\title{
A double blind comparative study of sulphasalazine and hydroxychloroquine in rheumatoid arthritis: evidence of an earlier effect of sulphasalazine
}

\author{
IKE H NUVER-ZWART, PIET L C M VAN RIEL, LEVINUS B A VAN DE PUTTE, \\ AND FRANK W J GRIBNAU \\ From the Department of Rheumatology, University Hospital, Geert Grooteplein Zuid 8, 6500 HB Nijmegen, \\ The Netherlands
}

SUMMARY In a double blind, single observer, 48 week study the effects of sulphasalazine ( $2 \mathrm{~g}$ daily) and hydroxychloroquine (400 mg daily months $0-6$, thereafter $200 \mathrm{mg}$ daily) were compared in 60 patients with definite or classical rheumatoid arthritis. They had not been treated previously with second line drugs. The onset of response with sulphasalazine was earlier than with hydroxychloroquine. After 48 weeks a comparison of the treatments showed no statistically significant differences in disease activity variables. Adverse reaction was the main reason for withdrawal in the sulphasalazine group and lack of efficacy in the hydroxychloroquine group. All adverse reactions, one being agranulocytosis after eight weeks of sulphasalazine treatment, appeared in the first three months of treatment and were completely reversible.

Sulphasalazine (salicylazosulphapyridine) was introduced by Svartz in 1942 for the treatment of rheumatoid arthritis and ulcerative colitis, ${ }^{1}$ because it was thought to have antibacterial as well as antiinflamriatory actions. Despite promising results in open studies the drug fell out of favour for the treatment of rheumatoid arthritis after a publication by Sinclair and Duthie in $1948,{ }^{2}$ although in retrospect, their conclusions are questionable in view of many flaws in the study design. Not until three decades later, after the report of McConkey et al, ${ }^{3}$ was the interest in sulphasalazine for treating rheumatoid arthritis renewed.

In open studies of sulphasalazine in rheumatoid arthritis both McConkey et al and Bird et al found circumstantial evidence of a disease modifying effect. ${ }^{34}$ This finding was confirmed in double blind controlled studies comparing sulphasalazine with Dpenicillamine $^{5}$ and placebo ${ }^{6} 7$ and in open studies with sodium aurothiomalate ${ }^{8}$ and D-penicillamine. ${ }^{9} 10$ In these studies the efficacy of sulphasalazine proved to be similar to that of D-penicillamine and somewhat less than that of aurothiomalate. In

Accepted for publication 13 October 1988.

Correspondence to Dr Ike Nuver-Zwart, Department of Rheumatology, University Hospital, Geert Grooteplein Zuid 8, 6500 HB Nijmegen, The Netherlands.
January 1985 we started a double blind trial to compare sulphasalazine with hydroxychloroquine. The latter drug is a disease modifying drug of first choice for rheumatoid arthritis in a number of European countries. No comparisons of hydroxychloroquine and sulphasalazine have been published so far.

\section{Patients and methods}

Patients from five participating clinics were included in the study. All patients were seen by one observer. Sixty patients with definite or classical rheumatoid arthritis according to American Rheumatism Association criteria ${ }^{11}$ disease onset after age 16 , and between 18 and 75 years old entered the study. Patients with serious complicating illnesses or previous reactions to sulphonamides or salicylates were excluded. Also excluded were patients of both sexes with a desire for children and patients previously treated with other second line drugs. Corticosteroid treatment was not permitted for three months before and during the trial. All patients had active disease, which was not adequately controlled by non-steroidal anti-inflammatory drugs. Active disease was characterised by at least three of the following five criteria: seven or more joints painful or tender at motion; four or more swollen joints; 
morning stiffness lasting for at least one hour; Westergren erythrocyte sedimentation rate exceeding $28 \mathrm{~mm} / 1 \mathrm{st} \mathrm{h}$; and anaemia (haemoglobin $\leqslant 138 \mathrm{~g} / 1$ in men, $\leqslant 118 \mathrm{~g} / \mathrm{l}$ in women).

\section{DRUG ADMINISTRATION}

Concomitant treatment with non-steroidal antiinflammatory drugs in a stable dose for one month before entry was continued throughout the study as far as possible; no other concomitant drug treatment for rheumatoid arthritis was allowed, neither were intra-articular steroid injections. Double blinding was accomplished by a double dummy technique. Patients receiving hydroxychloroquine took $200 \mathrm{mg}$ twice a day for the first six months, thereafter $200 \mathrm{mg}$ once daily, according to the standard scheme. Patients receiving sulphasalazine took an initial dose of $500 \mathrm{mg} /$ day. At four-day intervals this was increased by $500 \mathrm{mg}$ to a maximum dose of $2 \mathrm{~g} /$ day.

\section{STUDY DESIGN}

The study was a 48 week parallel, double blind trial of hydroxychloroquine versus sulphasalazine. The patients entered the study over a period of 18 months and were allocated to receive either sulphasalazine or hydroxychloroquine using a blocked randomisation procedure. The patients were followed up at the outpatient clinic and were all seen by the same observer (IHNZ). The following assessments were recorded monthly: (a) duration of morning stiffness (in minutes); (b) grip strength using a sphygmomanometer (Martin Vigorimeter) ranging from 0 to $200 \mathrm{kPa}$; (c) patient pain assessment by analogue rating on a $10 \mathrm{~cm}$ line $(0=$ no pain, 10=severe pain); (d) patient general health assessment by analogue rating on a $10 \mathrm{~cm}$ line by asking the patient how he felt during the past week $(0=$ very well, $10=$ very bad $) ;(e)$ number of joints with pain on palpation or passive movement of a total of 53 joints; (f) number of swollen joints out of a total of 46 joints; (g) Ritchie articular index ranging from 0 to 78 .

Radiographs of hands and feet were obtained at weeks 0,24 , and 48 during the study. Tests for rheumatoid factor (Rose-Waaler and latex fixation test), folate, and vitamin $B_{12}$ were carried out at weeks 0,24 , and 48 . Additional laboratory tests (undertaken at the same time as the clinical assessments) included erythrocyte sedimentation rate, haemoglobin, white blood cell count and differential, platelet count, mean cell volume, creatinine, alkaline phosphatase, $S$-alanine aminotransferase, $\gamma$-glutamyltransferase, lactic dehydrogenase, and $C$ reactive protein. Measurements of total protein, protein electrophoresis for albumin, $\alpha_{1}, \alpha_{2}, \beta$, and $\gamma$-globulins, immunoglobulins $A, G$, and $M$, and. reticulocyte count were carried out at weeks $0,4,12 \underset{\text { के }}{\vec{F}}$ 24,36 , and 48 during the study. At the start of the study all patients were checked by an ophthalmolo흥 gist. Ophthalmological examination included deter mination of visual acuity, split lamp examination $\widehat{\nabla}$ ophthalmoscopy, electro-oculography, ${ }^{12}$ and visua field examination with the Umazume-Ohta test. ${ }^{10}$ All patients were checked in the event of visuab complaints; the patients receiving hydroxychloro quine were checked at least after one year.

ADVERSE REACTIONS

At each visit the patients were questioned abouto new symptoms. The relation between the trial drug treatment and any new symptom was discussed.

COMPLIA N C E

Return drug count was used to measure patient compliance.

\section{STATISTICAL ANALYSIS}

The comparison of treatment groups at baseline was by $t$ test for continuous variables and $\chi^{2}$ test fog categorical variables. For patients withdrawn before the end of the planned treatment period the las 5 observed value was used in the statistical analysio (end point analysis). ${ }^{14}$ In each patient the change from baseline was calculated as the score after treatment minus the baseline score. These changes were compared between treatment groups using two sample $t$ test. The changes within the groups were statistically tested using a paired $t$ test p Values $<0.05$ were considered significant. Thirty patients in each treatment group permits with $95 \%$ confidence the detection of a difference between two means of about one standard deviation.

\section{Results}

Sixty patients entered the study. At the start of the study the differences between the sulphasalazines and hydroxychloroquine treatment groups were not statistically significant either in clinical characteristic (Table 1 ) or in disease activity (Table 2 ).

Three patients withdrawn within the first month (two because of protocol violation and one because? of vomiting) were excluded from the analysis of efficacy. All 60 patients were included in the analysis of safety.

RESPONSE BY TREATMENT GROUP In the sulphasalazine treated group improvemen from baseline reached statistical significance aftep four weeks for the duration of morning stiffness grip strength, pain score, IgM, and IgG; after eight 
Table 1 Clinical characteristics at entry by treatment group

\begin{tabular}{|c|c|c|}
\hline Variable & $\begin{array}{l}\text { Sulphasalazine } \\
(n=30)\end{array}$ & $\begin{array}{l}\text { Hydroxychloroquine } \\
(n=30)\end{array}$ \\
\hline \multirow{3}{*}{$\begin{array}{l}\text { Mean age (range) } \\
\text { Sex (F/M) } \\
\text { Mean disease duration } \\
\text { in months (range) }\end{array}$} & $53 \cdot 5(22-75)$ & $53.0(22-72)$ \\
\hline & $20 / 10$ & $18 / 12$ \\
\hline & $10 \cdot 8(3-120)$ & $14 \cdot 8(3-165)$ \\
\hline \multirow{4}{*}{$\begin{array}{cc}\text { Anatomical } & \text { stage } \\
\text { (ARA) }^{*} & 2 \\
& 3 \\
4\end{array}$} & 21 & 16 \\
\hline & 9 & 13 \\
\hline & 0 & 1 \\
\hline & 0 & 0 \\
\hline \multirow{4}{*}{$\begin{array}{cc}\text { Functional class } & 1 \\
\text { (Steinbrocker) } & 2\end{array}$} & 4 & 1 \\
\hline & 15 & 15 \\
\hline & 10 & 14 \\
\hline & 1 & 0 \\
\hline \multicolumn{3}{|l|}{ Rheumatoid factor } \\
\hline$>1 / 40$ & 25 & 29 \\
\hline$\leqslant 1 / 40$ & 5 & 1 \\
\hline \multicolumn{3}{|l|}{ Number with } \\
\hline rheumatoid nodules & 6 & 6 \\
\hline
\end{tabular}

*ARA = American Rheumatism Association.

weeks for erythrocyte sedimentation rate and $\mathrm{C}$ reactive protein, after 12 weeks for Ritchie articular index, number of swollen joints, and IgA (Fig. 1); and after 20 weeks for number of tender joints.

After 24 weeks all clinical and laboratory parameters of disease activity, except haemoglobin, were statistically significantly improved (Table 2). This improvement lasted until the end of the study, except for general health.

In the hydroxychloroquine treated group improvement reached statistical significance in week 4 for IgM, in week 12 for number of swollen joints, in week 16 for duration of morning stiffness and Ritchie articular index, in week 20 for pain score, and in week 24 for erythrocyte sedimentation rate. After 24 weeks six of the 13 parameters of disease activity and after 48 weeks four of the 13 were statistically significantly improved (Table 2 ).

RESPONSE TO SULPHASALAZINE COMPARED WITH THAT TO HYDROXYCHLOROQUINE

The difference between the groups reached statistical significance in favour of sulphasalazine in week 8 for pain score; in weeks 8 and 16 for grip strength; for $\operatorname{IgA}$ in weeks 12 and 24 ; for IgM in week 12 ; and for IgG in weeks 4,12 , and 24 . In the second six months the difference between the treatment groups remained but reached statistical significance only in week 36 for IgA, IgM, and IgG and in week 48 for $\operatorname{Ig} \mathbf{A}$.

\section{PATIENT WITHDRAWAL AND ADVERSE REACTION}

After 48 weeks 21 patients continued to take sulphasalazine and 18 patients hydroxychloroquine. Table 3 gives the number of patients, type of adverse reaction, the time of observation, and the number and reasons for withdrawals. All adverse reactions in both treatment groups were observed in the first three months of treatment.

In the sulphasalazine group there were nine withdrawals. Of these, two were for non-drugrelated reasons, three because of lack of effect, and four due to adverse reactions. The most severe adverse reaction was agranulocytosis after eight

Table 2 Changes in clinical variables after 24 and 48 weeks of treatment with sulphasalazine or hydroxycholoroquine. Values are shown as mean (SD)

\begin{tabular}{|c|c|c|c|c|c|c|}
\hline \multirow[t]{2}{*}{ Variables } & \multicolumn{3}{|l|}{ Sulphasalazine } & \multicolumn{3}{|c|}{ Hydroxychloroquine } \\
\hline & $\begin{array}{l}W k 0 \\
(n=28)\end{array}$ & $\begin{array}{l}W k 24 \\
(n=28)\end{array}$ & $\begin{array}{l}W k 48 \\
(n=28)\end{array}$ & $\begin{array}{l}W k 0 \\
(n=29)\end{array}$ & $\begin{array}{l}W k 24 \\
(n=29)\end{array}$ & $\begin{array}{l}W k 48 \\
(n=29)\end{array}$ \\
\hline Morning stiffness (min) & $143(100)$ & $44(73)^{* *}$ & $67(101)^{*}$ & $118(97)$ & $49(73)^{* *}$ & 67 (94) \\
\hline $\begin{array}{l}\text { Grip strength (kPa) } \\
\text { Pain }(10 \mathrm{~cm} \text { analogue }\end{array}$ & $33(27)$ & $47(27)^{* *}$ & $48(32)^{* *}$ & $32(24)$ & $37(22)$ & $36(24)$ \\
\hline scale) & $5 \cdot 00(2 \cdot 16)$ & $3 \cdot 16(2 \cdot 59)^{* *}$ & $3 \cdot 28(2 \cdot 80)^{* *}$ & $4 \cdot 17(1.96)$ & $2.52(1.98)^{* *}$ & $3 \cdot 30(2 \cdot 34)^{*}$ \\
\hline $\begin{array}{l}\text { General health }(10 \mathrm{~cm} \\
\text { analogue scale) }\end{array}$ & $3.56(2.46)$ & $2 \cdot 27(1 \cdot 87)^{* *}$ & $2 \cdot 48(2 \cdot 10)$ & $2.95(2 \cdot 22)$ & $1.97(1.73)^{*}$ & $2 \cdot 52(1 \cdot 78)$ \\
\hline Tender joints (No) & $15(8)$ & $11(10)^{*}$ & $11(10)^{*}$ & $16(7)$ & $12(9)$ & $11(8)^{* *}$ \\
\hline Swollen joints (No) & $14(6)$ & $10(7)^{* *}$ & $10(8)^{*}$ & $14(5)$ & $12(7)$ & $12(7)$ \\
\hline Ritchie articular index & $13 \cdot 6(6 \cdot 7)$ & $8.6(9.9)^{* *}$ & $8.8(10 \cdot 0)^{* *}$ & $14 \cdot 1(6 \cdot 5)$ & $10 \cdot 2(7 \cdot 1)^{* *}$ & $9.6(7 \cdot 1)^{* *}$ \\
\hline ESR $\ddagger$ (mm/1st h) & $43(30)$ & $25(19)^{* *}$ & $30(22)^{* *}$ & $41(24)$ & $28(24)^{*}$ & $33(25)$ \\
\hline CRP¥ (mg/1) & $40(50)$ & $14(17)^{* *}$ & $24(27)^{*}$ & $40(54)$ & $30(36)$ & $28(34)$ \\
\hline Haemoglobin (g/l) & 129 (16) & $126(14)$ & $126(14)$ & $130(14)$ & $127(15)$ & $130(14)$ \\
\hline $\operatorname{IgA}(g / 1)$ & $3.52(2.02)$ & $3.19(2.00)^{* *} \dagger$ & $2.99(1.91)^{* *} \dagger$ & $3.46(1.82)$ & $3.60(1.42)$ & $3.41(1.42)$ \\
\hline $\operatorname{IgM}(g / 1)$ & $2.45(1.65)$ & $1.88(1 \cdot 11)^{* *}$ & $1.90(1.17)^{* *}$ & $1.87(0.97)$ & $1.67(0.97)^{* *}$ & $1.66(1.07)^{* *}$ \\
\hline $\operatorname{IgG}(g / 1)$ & $15.64(3.92)$ & $14.07(3.88)^{* *} \dagger$ & $14 \cdot 00(4 \cdot 11)^{* *}$ & $14.66(3.67)$ & $14 \cdot 81(4 \cdot 22)$ & $14.31(3.69)$ \\
\hline
\end{tabular}

${ }^{*} \mathrm{p}<0.05 ;{ }^{*} \mathrm{p} \leqslant 0.01$ - difference from baseline within treatment group by paired Student's $t$ test. $\dagger \mathrm{p}<0.05$-difference between treatment groups by unpaired Student's $t$ test.

$\mp E S R=$ erythrocyte sedimentation rate; $C R P=C$ reactive protein. 
MORNING STIFFNESS IN MINUTES

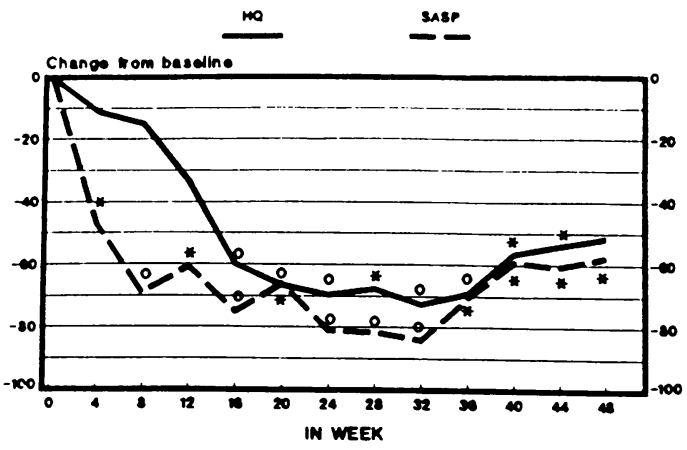

GENERAL HEALTH

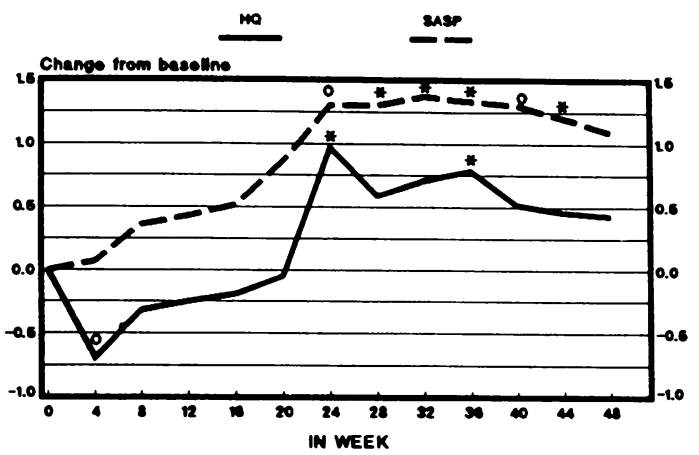

SWOLLEN JOINTS MUMBER

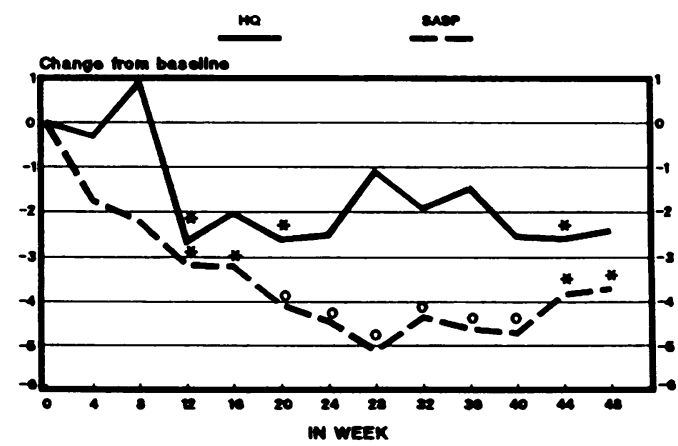

PAIN SCORE

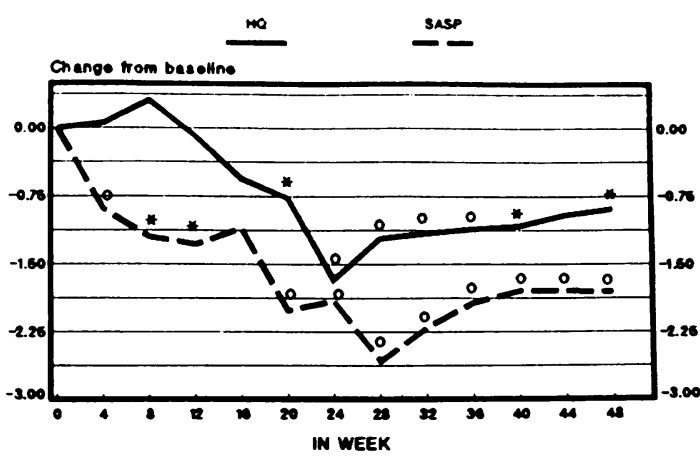

GRIP STRENGTH in $\mathrm{kPa}$

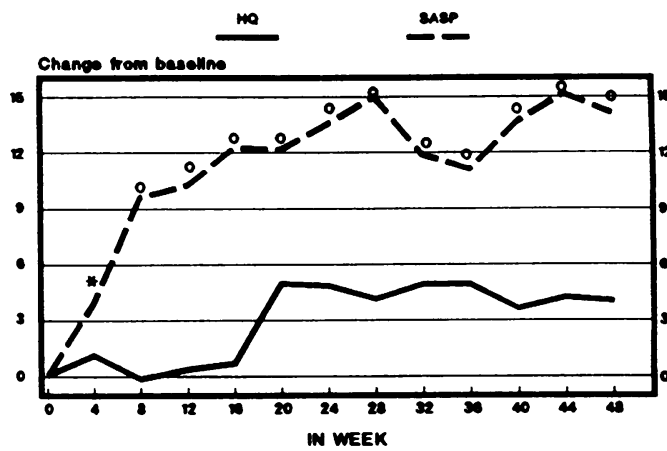

RITCHIE ARTICULAR INDEX

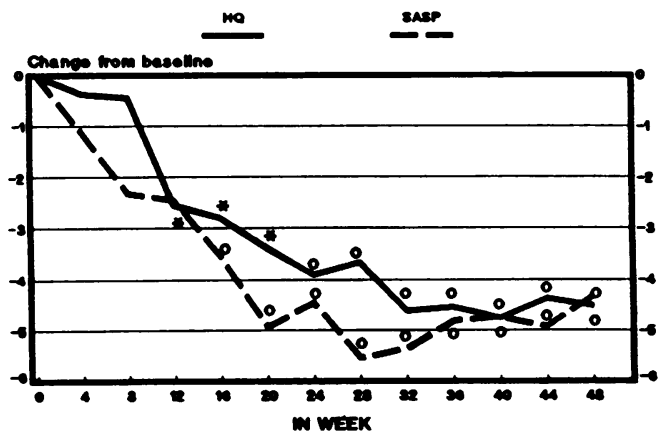


ESR in $\mathrm{mm}$

in 1at hour

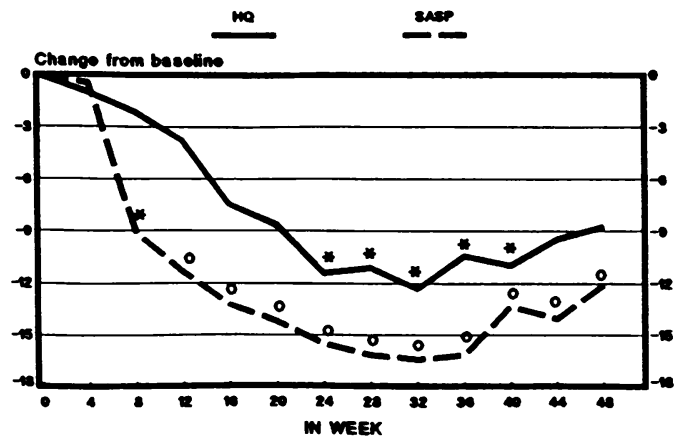

CRP

In $\mathbf{m g h}$

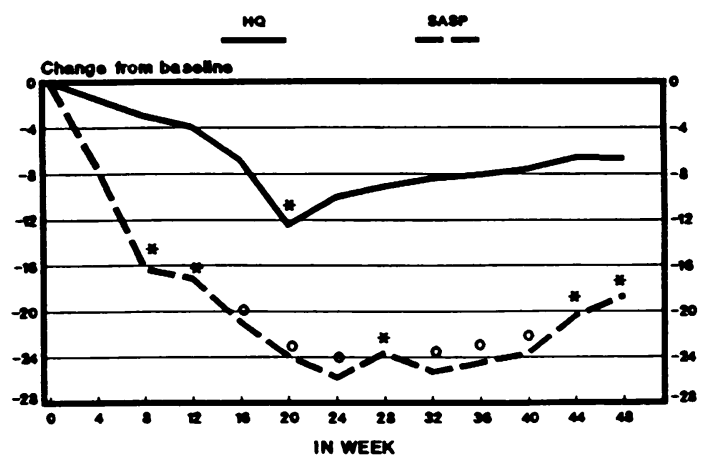

Fig. 1 Changes over time in eight disease activity variables for 57 patients (29 in the hydroxychloroquine group, 28 in the sulphasalazine group). All variables are expressed as mean changes in the scores from baseline. $\bigcirc=p \leqslant 0.01$, change from baseline within treatment group, paired t test; ${ }^{*}=p<0.05$, change from baseline within treatment group, paired test.

Table 3 Number of adverse reactions and withdrawals after 48 weeks

\begin{tabular}{|c|c|c|c|c|c|c|}
\hline \multirow{2}{*}{ Adverse reaction } & \multicolumn{3}{|c|}{ Sulphasalazine } & \multicolumn{3}{|c|}{ Hydroxychloroquine } \\
\hline & $\begin{array}{l}\text { Number of } \\
\text { patients }\end{array}$ & $\begin{array}{l}\text { Week of } \\
\text { observation }\end{array}$ & $\begin{array}{l}\text { Number of } \\
\text { withdrawals }\end{array}$ & $\begin{array}{l}\text { Number of } \\
\text { patients }\end{array}$ & $\begin{array}{l}\text { Week of } \\
\text { observation }\end{array}$ & $\begin{array}{l}\text { Number of } \\
\text { withdrawals }\end{array}$ \\
\hline \multicolumn{7}{|l|}{ Drug related } \\
\hline Nausea/vomiting & 6 & $\begin{array}{l}0-4,1-10,5 \\
2-4,4-15,11\end{array}$ & 3 & 4 & $\begin{array}{l}0-6,2-4, \\
2-5,2-6\end{array}$ & \\
\hline Borborygmi & & & & 1 & $0-11$ & 1 \\
\hline Bitter taste & 1 & $6-12$ & & & & \\
\hline Liver function abnormal & 1 & $4-12$ & & 2 & $4-12,8-24$ & \\
\hline Agranulocytosis & 1 & $8-10$ & 1 & & & \\
\hline Total drug related & 9 & & 4 & 7 & & 1 \\
\hline \multicolumn{7}{|l|}{ Not drug related } \\
\hline Intercurrent illness & & & & 1 & 8 & 1 \\
\hline Lack of cooperation & 1 & 9 & 1 & & & \\
\hline Protocol violation & 1 & 2 & 1 & 1 & 2 & 1 \\
\hline Total not drug related & 2 & & 2 & 2 & & 2 \\
\hline Lack of efficacy & 3 & $24,24,43$ & 3 & 9 & $\begin{array}{l}24,24,24 \\
24,24,30 \\
32,32,40\end{array}$ & 9 \\
\hline Totals & & & 9 & & & 12 \\
\hline
\end{tabular}

weeks of treatment with sulphasalazine. In this case the white cell count fell to $1 \cdot 1 \times 10^{9} / 1$ (neutrophils $0 \%)$. Drug treatment was stopped and the patient was treated in hospital by reverse barrier nursing. The white cell count rose to $5 \cdot 0 \times 10^{9} / 1$ after 13 days. Three patients withdrew because of severe nausea/ vomiting.

Other adverse reactions were a transient slight liver function abnormality observed in one patient, maximum alkaline phosphatase $162 \mathrm{U} / \mathrm{l}$ (normal $\leqslant 120 \mathrm{U} / 1)$, maximum $\gamma$-glutamyltransferase $41 \mathrm{U} / 1$ (normal $\leqslant 36 \mathrm{U} / 1$ ). Drug treatment was not stopped. A bitter taste developed in one patient and nausea in three other patients. An isolated slight increase in lactic dehydrogenase to a maximum of $451 \mathrm{U} / \mathrm{l}$ (normal $\leqslant 275 \mathrm{U} / \mathrm{l}$ ) was found in five patients. During the study folate decreased in 13 patients, while an increase was observed in seven.

In the hydroxychloroquine group there were 12 withdrawals. Of these, two were for non-drug- 
related reasons, nine because of lack of effect, and one due to borborygmi. Other adverse reactions were mild nausea in four patients and transient slight liver function abnormality in two patients, maximum alkaline phosphatase $134 \mathrm{U} /$, maximum $S$-alanine aminotransferase $38 \mathrm{U} / 1$ (normal $\leqslant 25$ $\mathrm{U} / \mathrm{l}$ ), maximum $\gamma$-glutamyltransferase $57 \mathrm{U} / \mathrm{l}$. Drug treatment was not stopped. An isolated slight increase in lactic dehydrogenase to a maximum of $332 \mathrm{U} / \mathrm{l}$ was found in four patients. Folate decreased in four patients and increased in 19 patients during the study.

In both groups white blood cell counts and differential counts, with the one exception mentioned, platelet counts, creatinine, and vitamin $B_{12}$ varied within normal ranges.

\section{Discussion}

We compared the efficacy and toxicity of sulphasalazine and hydroxychloroquine in the treatment of patients with active rheumatoid arthritis not previously treated with disease modifying drugs. Both drugs have been shown in earlier placebo controlled studies to have a disease modifying effect. ${ }^{6} 715-18$ We are aware that the dose reduction of hydroxychloroquine after six months in the study might have influenced the results. We felt justified in doing this, however, because it is a widely accepted practice in order to lower the toxicity rate, especially ocular toxicity. ${ }^{19}$

We found that treatment with sulphasalazine apparently has some advantages over the use of hydroxychloroquine, notably the quicker response. Within the sulphasalazine group significant improvement from baseline was recorded for duration of morning stiffness, grip strength, and pain score after only four weeks of treatment. This was followed by significant improvement in erythrocyte sedimentation rate and $C$ reactive protein (week 8), Ritchie articular index and number of swollen joints (week 12), and, finally, number of tender joints (week 20) and general health (week 24). In the hydroxychloroquine group a significant change from baseline was not found until week 12-namely, for number of swollen joints. Later on, Ritchie articular index and duration of morning stiffness (week 16), pain score (week 20), erythrocyte sedimentation rate (week 24), and number of tender joints (week 28) improved. This group showed no significant improvement in grip strength and improvement only in week 20 for $C$ reactive protein. It therefore appears that the onset of response in the sulphasalazine group was about eight weeks earlier than that in the hydroxychloroquine group. A similar early response to treatment with sulphasalazine has been noted by other investigators. ${ }^{79}$ Our data also indicate that the response to treatment was better in the sulphasala- $\vec{F}$ zine group than in the hydroxychloroquine group as 11 disease activity parameters improved during? sulphasalazine treatment as compared with only $\frac{\bar{\sigma}}{\bar{n}}$ four in the hydroxychloroquine group. Furthermore, at some times during the study there were significant $\varrho$ differences between the groups for several parameters.œ Finally, the number dropping out owing to lack of $\vec{\circ}$ effect was nine in the hydroxychloroquine group and three in the sulphasalazine group. This difference $\vec{\omega}$ was not significant (Fisher's exact test $p=0 \cdot 1041$ ).

On the other hand, there were more side effects and more patients withdrawing owing to toxicity in + the sulphasalazine group than in the hydroxychloro-cr quine group. In the hydroxychloroquine group $\omega_{\infty}^{\omega}$ adverse reactions were found in $7 / 30(23 \%)$ of the patients. Most frequently we observed gastrointes- - 군 tinal side effects $(4 / 30 ; 13 \%)$. Retinopathy, the most ${ }^{-}$ serious toxic effect of hydroxychloroquine treatment, ${ }^{20}$ did not occur in our patients. All adverse reactions were mild and reversible. Only one patient $\overrightarrow{0}$ dropped out in this group. In the sulphasalazines group $9 / 30(30 \%)$ of the patients had side effects, allo of them reversible and none of a kind that has not? been reported in previous studies. ${ }^{5-10}$ Nausea and릉 vomiting was the most frequent side effect present ing $6 / 30(20 \%)$ of the patients at some point, mostly® early in the study. The percentage of adverse reactions, particularly gastrointestinal toxicities, is probably dose dependent. In studies using a dose of $3 \mathrm{~g}$ daily $^{67}$ the percentage of side effects was reportedly higher than in those with a daily dose of $2 \mathrm{~g},{ }^{58}$ whereas the clinical efficacy was apparently the same. The same observation has been made foro gastrointestinal side effects in patients treated with sulphasalazine for inflammatory bowel disease. ${ }^{21}{ }^{220}$ A few other side effects were found in our study Serum lactic dehydrogenase values were occasionallyo increased in some patients, probably owing to slights haemolysis, as suggested by mildly increased reticulocyte counts. No clinically significant haemolysiš occurred in the sulphasalazine group, however. The most severe side effect we observed was agranulo 0 cytosis, occurring after eight weeks of treatmentw with sulphasalazine. Bone marrow examination in this case showed a maturation defect of myeloco poiesis. When drug treatment was stopped the white् blood cell count rose to normal within two weeks? Recently, Capell et al described seven cases ofo leucopenia, all occurring in the first three months o $\vec{P}$ treatment and all showing rapid recovery (withirg three weeks) when treatment was stopped. ${ }^{23} \mathrm{~N} \Phi$ clear relation was found between leucopenia an ${ }_{5}$ drug dose or acetylator status. The one patienf tissue typed in their series had an HLA haplotype 
A1, A3, B7, B8, DR3, and DR4. Interestingly, the patient with agranulocytosis also possessed the HLA-B7 phenotype. Further studies are currently in progress to investigate the possibility that the development of sulphasalazine induced leucopenia is genetically determined. Eight cases of leucopenia were reported by Amos et al in a study of 774 patients treated with sulphasalazine. ${ }^{24}$ Again, the leucopenia was reversible and occurred in the first three months of treatment in all cases. In our study four $(13 \%)$ of 30 patients in the sulphasalazine group withdrew owing to toxicity, a percentage comparable with that in other studies using $2 \mathrm{~g}$ daily ${ }^{8}$ and lower than that in studies with a daily dose of $3 \mathrm{~g}(30 \%) .^{67}$

We conclude from our data that sulphasalazine induces an earlier and slightly better response than hydroxychloroquine. The earlier response to sulphasalazine, especially, may be an important advantage in terms of quality of life for patients with rheumatoid arthritis as other disease modifying drugs, such as D-penicillamine and gold compounds, are generally effective only after three to four months. Recent studies have shown that sulphasalazine has the same efficacy as D-penicillamine ${ }^{510}$ and is only slightly less effective than aurothiomalate. ${ }^{68}$ With a daily dose of $2 \mathrm{~g}$ sulphasalazine the withdrawal rate due to adverse reactions is lower than that with aurothiomalate and D-penicillamine. Adverse reactions, including leucopenia, are mainly observed in the first three months of treatment. Therefore our policy is to check blood counts once a fortnight for the first three months, thereafter every four to eight weeks. Furthermore, patients are instructed to contact us if they develop a fever.

This study was supported by a grant from Pharmacia Sweden and made possible thanks to the cooperation of the rheumatologists from the following hospitals: Stadsmaten and Ziekenzorg in Enschede, Mariaziekenhuis in Tilburg, and the Maartenskliniek in Nijmegen, The Netherlands.

\section{References}

1 Svartz N. The treatment of rheumatic polyarthritis with acid azo compounds. Rheumatism 1948; 4: 180-6.

2 Sinclair R J G, Duthie J J R. Salazopyrin in the treatment of rheumatoid arthritis. Ann Rheum Dis 1949; 8: 226-31.

3 McConkey B, Amos R S, Durham S. Sulphasalazine in rheumatoid arthritis. Br Med J 1980; 280: 442-4.

4 Bird H A, Dixon J S, Pickup M E et al. A biochemical assessment of sulphasalazine in rheumatoid arthritis. $J$ Rheumatol 1982; 9: 36-45.

5 Neumann V C, Grindulis K A, Wright V. Comparison between penicillamine and sulphasalazine in rheumatoid arthritis: LeedsBirmingham trial. Br Med J 1983; 287: 1099-102.

6 Pullar T, Hunter J A, Capell H A. Sulphasalazine in rheumatoid arthritis: a double blind comparison of sulphasalazine with placebo and sodium aurothiomalate. $\mathrm{Br}$ Med J 1983; 287: $1102-4$.

7 Pinals R S, Kaplan S B, Lawson J G, Hepburn B. Sulfasalazine in rheumatoid arthritis: a double-blind, placebo-controlled trial. Arthritis Rheum 1986; 29: 1427-34.

8 Bax D E, Amos R S. Sulphasalazine: a safe, effective agent for prolonged control of rheumatoid arthritis. A comparison with sodium aurothiomalate. Ann Rheum Dis 1985; 44: 194-8.

9 Farr M, Tunn E, Crockson A P, Bacon P A. The long term effects of sulphasalazine and a comparative study with penicillamine. Clin Rheumatol 1984; 4: 473-82.

10 Grindulis K A, McConkey B. Outcome of attempt to treat rheumatoid arthritis with gold, penicillamine, sulphasalazine or dapsone. Ann Rheum Dis 1984; 43: 398-401.

11 Ropes M W. Diagnostic criteria for rheumatoid arthritis 1958 revision. Ann Rheum Dis 1959; 18: 49-54.

12 Pinckers A, Broekhuyse $R$ M. The EOG in rheumatoid arthritis. Acta Ophthalmol (Copenh) 1983; 61: 831-7.

13 Pinckers A. The Umazume-Ohta test. Modern Problems of Ophthalmology 1976; 17: 175-8.

14 Gould A L. A new approach to the analysis of clinical drug trials with withdrawals. Biometrics $1980 ; 36$ : 721-7.

15 Cohen A S, Calkins E. A controlled study of chloroquine as an antirheumatic agent. Arthritis Rheum 1958; 1: 297-312.

16 Hamilton E B D, Scott J T. Hydroxychloroquine sulphate (Plaquenil) in the treatment of rheumatoid arthritis. Arthritis Rheum 1962; 5: 502-12.

17 Freedman A, Steinberg V L. Chloroquine in rheumatoid arthritis: a double blind trial of treatment for one year. Ann Rheum Dis 1960; 19: 243-50.

18 Mainland D, Sutcliffe M I. Hydroxychloroquine sulfate in rheumatoid arthritis: a 6-month double blind trial. Bull Rheum Dis 1962; 12: 287-90.

19 Mackenzie A H. Dose refinements in long-term therapy of rheumatoid arthritis with antimalarials. Am J Med 1983; 75: 40-5.

20 Maksymowych W. Antimalarials in rheumatology: efficacy and safety. Semin Arthritis Rheum 1987; 16: 206-21.

21 Nielsen $\mathrm{O} \mathrm{H}$. Sulfasalazine intolerance: a retrospective survey of the reasons for discontinuing treatment in patients with chronic inflammatory bowel disease. Scand J Gastroenterol 1982; 17: 389-93.

22 Khan A K A, Howes D T, Piris J, Truelove S C. Optimum dose of sulphasalazine for maintenance treatment in ulcerative colitis. Gut 1980; 21: 232-40.

23 Capell H A, Pullar T, Hunter J A. Comparison of white blood cell dyscrasias during sulphasalazine therapy of rheumatoid arthritis and inflammatory bowel disease. Drugs Contents 1986; 321 (suppl 1): 44-8.

24 Amos R S, Pullar T, Capell H A. Sulphasalazine for rheumatoid arthritis: toxicity in 774 patients monitored for one to 11 years. Br Med J 1986; 293: 420-3. 